\title{
КОМБИНИРОВАННЫЙ МИКРОКАНАЛЬНЫЙ РЕАКТОР ДЛЯ ПАРЦИАЛЬНОГО ОКИСЛЕНИЯ МЕТАНА
}

\author{
Л. Л. Макаршин, Д. В. Андреев, А. Г. Грибовский
}

\begin{abstract}
Проведено исследование процесса парциального окисления метана (ПОМ) для получения синтез-газа в комбинированном каталитическом микроканальном реакторе (МКР), состоящем из двух последовательных зон - зоны 1 малого объёма и зоны 2 большего объёма, связанных между собой по теплопередаче. Установлено, что при больших входных потоках реакцион-

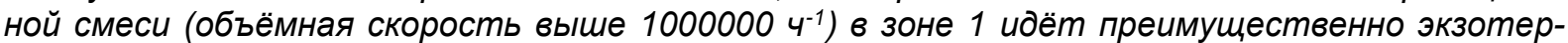
мическая реакция полного окисления метана, а в зоне 2 - эндотермические реакции паровой и углекислотной конверсии метана. Такая комбинация зон в микроканальном реакторе позволяет разгрузить энергонапряженность и, следовательно, уменьшить повышение температуры на фрронтальной кромке микроканальных пластин, обычно возникающее в ходе процесса ПОМ. Показано, что проведение процесса ПОМ в комбинированном МКР, когда реакционная смесь последовательно проходит через зону 1 и зону 2, существенно увеличивает глубину протекания процесса ПОМ и увеличивает содержание синтез-газа на выходе за счёт передачи тепла из зоны 1 в зону 2. Так, при $750{ }^{\circ} \mathrm{C}$ и объёмной скорости входного потока 240000 ч $^{-1}$ концентрация водорода и моноксида углерода на выходе составляет 30,1 и 23,7 об.\% соответственно. Тогда как проведение процесса ПОМ только в одной зоне 2 МКР даёт на выходе концентрацию водорода и моноксида уәлерода только 23,2 и 20,1 об. \% соответственно.
\end{abstract}

Ключевые слова: парциальное окисление метана, полное окисление метана, паровая конверсия метана, углекислотная конверсия метана, синтез-газ, водород, моноксид углерода, микроканальный каталитический реактор, микроканальные каталитические пластины, теплопередача.

\section{ВВЕДЕНИЕ}

Синтез-газ (смесь водорода и моноксида углерода) широко используют в крупнотоннажных химических процессах, таких как синтез аммиака, метанола, высших спиртов и альдегидов, в процессе Фишера-Тропша и др. В энергетике синтез-газ и водород можно применять в топливных элементах для производства экологически «чистого» тепла и энергии [1, 2].

Традиционным способом получения синтез-газа является эндотермический процесс паровой конверсии природного газа на никелевых катализаторах $[3,4]$. Обычно в реакторы с неподвижным слоем катализатора на вход подаётся смесь метана (природного газа) и воздуха в соотношении, удовлетворяющем брутто-уравнению реакции (1) парциального окисления метана:

$$
\begin{aligned}
& \mathrm{CH}_{4+0,5 \mathrm{O}_{2}=\mathrm{CO}+\mathrm{H}_{2},} \\
& \Delta H=-35,7 \text { кДж/моль. }
\end{aligned}
$$

Этот процесс является трехстадийным:

$$
\begin{gathered}
0,25 \mathrm{CH}_{4}+0,5 \mathrm{O}_{2}=0,25 \mathrm{CO}_{2}+0.5 \mathrm{H}_{2} \mathrm{O}, \\
\Delta H=-802,3 \text { кДж/моль },
\end{gathered}
$$

$$
\begin{gathered}
0,25 \mathrm{CH}_{4}+0,5 \mathrm{H}_{2} \mathrm{O}=0,5 \mathrm{H}_{2}+0,25 \mathrm{CO}_{2}, \\
\Delta H=206,1 \text { кДж/моль, } \\
0,5 \mathrm{CO}_{2}+0,5 \mathrm{CH}_{4}=\mathrm{CO}+\mathrm{H}_{2}, \\
\Delta H=246,5 \text { кДж/моль }
\end{gathered}
$$

при этом первая стадия является очень быстрой и высокоэкзотермической, остальные две - более медленными и эндотермическими.

В работе [5] исследовали процесс ПОМ на $\mathrm{Pd} / \mathrm{Al}_{2} \mathrm{O}_{3}$ и $\mathrm{Rh} / \mathrm{Al}_{2} \mathrm{O}_{3}$ катализаторах, закреплённых на стенках микроканального реактора. Исследования показали, что внутри каталитического канала существуют две последовательные области: область полного окисления и область паровой конверсии метана, причём основная реакция образования синтез-газа протекает именно во второй области. Изучение процесса ПОМ в пилотной установке на блочном катализаторе, содержащем

Pt-Pd [6], показало, что в лобовом слое блока протекает полное окисление метана (реакция 1), а в последующих слоях - паровая и углекислотная конверсия метана (реакции 2 и 3), вследствие чего по длине блока наблюдается большой градиент температуры: лоПОЛЗУНОВСКИЙ ВЕСТНИК № 42018 
бовой слой оксидного катализатора из-за низкой теплопроводности сильно перегревается - его температура на 200-400 ${ }^{\circ} \mathrm{C}$ выше, чем в остальной части реактора, что приводит к неэффрективной работе катализатора и к преждевременному снижению его активности.

Таким образом, катализатор должен иметь высокую теплопроводность, чтобы обеспечить эффрективный перенос тепла из зон экзотермической реакции метана в зону эндотермических реакций конверсии метана.

Этим условиям может удовлетворить реактор с микроканальной структурой. Каталитические микрореакторы представляют собой, как правило, слоистую структуру, состоящую из набора металлических пластин с каналами субмиллиметровых размеров, на поверхность которых нанесён катализатор. Благодаря малым размерам каналов реализуются высокие значения соотношения поверхность/объем и очень высокие скорости массо- и теплопереноса - на 1-2 порядка выше, чем в системах с массивным слоем катализатора, что существенно уменьшает температурный градиент вдоль зоны реакции [7]. Кроме того, благодаря малым размерам каналов достигается ламинарное течение газового потока с равномерным распределением по скоростям или по времени контакта реагентов с катализатором [8], при этом гасятся нежелательные радикальные процессы, что увеличивает выход полезных продуктов реакции [9].

Преимуществом микроканальных реакторов является и то, что они позволяют гибко изменять свою топологию - могут состоять из нескольких зон, причём эти зоны можно располагать относительно друг друга так, что между ними будет осуществляться эффективный тепловой контакт, когда тепло из зоны экзотермического процесса можно передать в зону, где идёт эндотермический процесс.

В настоящей работе проведены эксперименты с использованием комбинированного микроканального реактора, состоящего из двух зон. В первой зоне при коротких временных промежутках контакта протекает экзотермический процесс полного окисления метана. Во второй зоне, в которой время контакта на порядок больше, протекают эндотермические процессы паровой и углекислотной конверсии метана. Проведено сравнение работы комбинированного МКР в разных режимах, когда исходная смесь метана и воздуха поступает только в первую зону или только во вторую зону, а также последовательно в первую и вторую зону.

\section{ЭКСПЕРИМЕНТАЛЬНАЯ ЧАСТЬ}

\section{Нанесение катализатора на микроканальные пластины}

Процесс ПОМ в комбинированном микроканальном реакторе (МКР) проводили на катализаторе состава $\mathrm{Pt}$ (2\% масс.)/ $\mathrm{Al}_{2} \mathrm{O}_{3}$, закреплённого на металлических микроканальных пластинах (МКП). Процедура закрепления катализатора на МКП подробно описана в работе [10]. На рисунке 1 приводится фотография МКП, изготовленных методом фррезерования и используемых для проведения эксперимента.

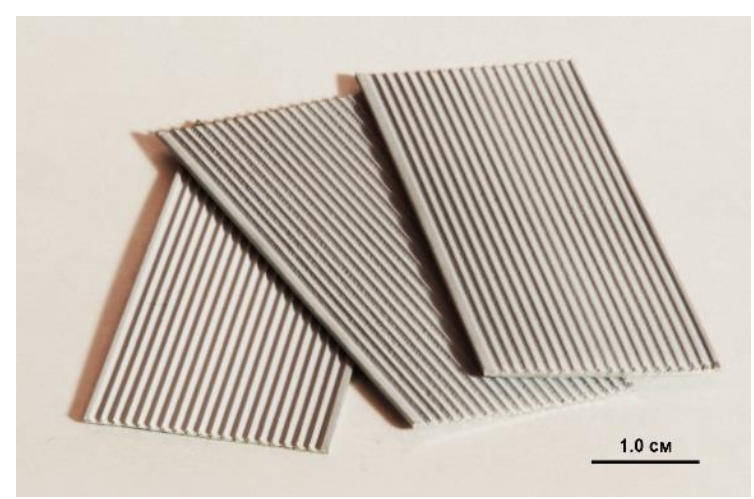

Рисунок 1 - Фотография МКП с нанесённым катализатором

Масса закреплённого на одной пластине катализатора Pt (2\% масс.)/ $/ \mathrm{Al}_{2} \mathrm{O}_{3}$ составила 40 мг. Таким образом, в зоне 1 МКР общая масса катализатора, нанесённого на обе стороны пяти пластин, составила 200 мг, а масса катализатора на одной пластине зоны 2-40 мг.

\section{Экспериментальная установка}

Для испытания МКР в процессе ПОМ метана использовали установку, изготовленную в Институте катализа СО РАН. Схема установки приведена ранее в работе [11]. Нагрев МКР осуществляли при помощи электрической печи, температуру в которой поддерживали постоянной при помощи ПИД-регулятора. Температура в ходе экспериментов составляла $750{ }^{\circ} \mathrm{C}$.

Скорость подачи воздуха и метана в реактор регулировали с помощью регуляторов расхода газа РРГ (АО СКБ Катализаторов, Россия), диапазон подачи составлял 400-5000 мл/мин. Газовая смесь, подаваемая на вход МКР, имела следующий состав: $\mathrm{O}_{2}-$ $14,8 \%, \mathrm{~N}_{2}-55.6 \%, \mathrm{CH}_{4}-29,6 \%$. Отбор газовых проб на выходе из реактора делали после достижения теплового равновесия МКР 
с муфельной печью, а регистрацию продуктов реакции $\mathrm{H}_{2}, \mathrm{CH}_{4}, \mathrm{CO}$ и $\mathrm{CO}_{2}$ проводили после отделения воды из выходной смеси при помощи ловушки, охлаждаемой смесью воды и льда. Газохроматографический анализ проводили с помощью хроматографа (ЛХМ-8МД, Россия) с детектором по теплопроводности на колонке с цеолитом $\mathrm{CaX}$, а для анализа водорода - колонку с Сибунитом. В качестве газа-носителя использовали аргон.

\section{Микроканальный реактор}

В работе использовали специально сконструированный МКР (рисунок 2), состоящий из двух зон, разделённых металлической пластиной толщиной 1 мм. Такая конструкция реактора обеспечивала хороший тепловой контакт между зонами. Корпус реактора с внешним размером $30 \times 80 \times 12$ мм был изготовлен из жаропрочной стали марки 20X23H18. В зоне 1 (рисунок 2 а) находится одна МКП, содержащая 10 каналов трапецеидального сечения (ширина верхней части 0,7 мм, нижней части 0,3 мм, глубина 0,5 мм) и длиной 50 мм со свободным объёмом $0,12 \mathrm{~cm}^{3}$.
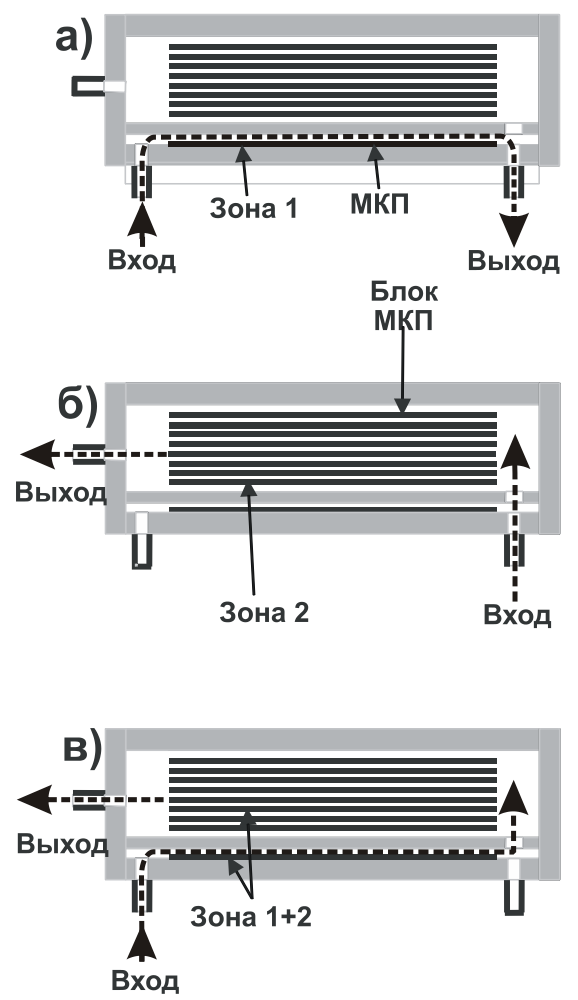

Рисунок 2 - Структура комбинированного МКР. Схема движения реакционной смеси показана пунктиром

В зоне 2 (рисунок 2 в) находился блок из пяти МКП с общим количеством каналов 50.
В этом случае свободный объем был почти на порядок больше и составил $1,14 \mathrm{~cm}^{3}$. Такая конструкция комбинированного МКР позволила исследовать процесс ПОМ при различных сочетаниях рабочих зон 1 и 2. Так, при реализации варианта «а» рисунка 2 входной поток реагентов поступает только в зону 1. При реализации варианта «б» рисунка 2 реагенты поступают только в зону 2. В комбинированном режиме исходная реакционная смесь последовательно поступает в зону 1 и 2 (рисунок 2 в).

В качестве основных параметров, описывающих ПОМ, использовали конверсию метана $\mathrm{X}_{\mathrm{CH} 4}$ и селективность по моноксиду углерода $\mathrm{Sco}$, которые рассчитывали по данным хроматографического анализа. Так как реакция ПОМ происходит с изменением числа молей, а азот воздуха является инертным газом и в реакции не участвует, то соотношение между объёмными потоками на входе и на выходе из реактора описывается следующим соотношением:

$$
U^{0} \cdot\left[N_{2}^{0}\right]=U \cdot\left[N_{2}\right],
$$

где $U^{0}$ и $U$ - объёмные потоки газа на входе и на выходе реактора соответственно, а $\left[N_{2}^{0}\right]$ и $\left[N_{2}\right]$ - объёмные концентрации азота на входе и на выходе микрореактора соответственно. Тогда конверсию метана можно рассчитать по следующей формуле

$$
X_{C H 4}=100 \% \cdot \frac{C H_{4}^{0}-\frac{N_{2}^{0}}{N_{2}} \cdot \mathrm{CH}_{4}}{C H_{4}^{0}},
$$

где $\left[\mathrm{CH}_{4}^{0}\right]$ и $\left[\mathrm{CH}_{4}\right]$ - объёмные концентрации метана на входе и на выходе микрореактора соответственно. Селективность по моноксиду углерода рассчитывали по соотношению

$$
S_{C O}=\frac{[\mathrm{CO}]}{\frac{\left[\mathrm{N}_{2}\right]}{\left[\mathrm{N}_{2}^{0}\right]} \cdot\left[\mathrm{CH}_{4}^{o}\right]-\left[\mathrm{CH}_{4}\right]} \cdot 100 \%,(7)
$$

где [CO] - объёмная концентрация моноксида углерода на выходе из микрореактора.

Объёмную скорость подачи газа рассчитывали по формуле:

$$
G H S V=\frac{U^{0}}{V_{\text {zone }}},
$$




\section{КОМБИНИРОВАННЫЙ МИКРОКАНАЛЬНЫЙ РЕАКТОР ДЛЯ ПАРЦИАЛЬНОГО ОКИСЛЕНИЯ МЕТАНА}

\section{РЕЗУЛЬТАТЫ И ОБСУЖДЕНИЕ}

Были проведены три серии экспериментов для исследования процесса ПОМ с использованием различных зон МКР: 1) испытание зоны 1; 2) испытание зоны 2; 3) испытание МКР при последовательно включённых зонах 1 и 2.

\section{Испытание зоны 1}

Испытания зоны 1 МКР проводили при $750{ }^{\circ} \mathrm{C}$ при закрытом выходе из зоны 2 (рисунок 2 а). В этом случае исходная смесь, поступающая на вход МКР, проходила только через зону 1. Для значений входного потока 400-5000 мл/мин значения объёмной скорости

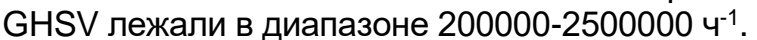

На рисунке 3 приведены зависимости концентраций реагентов на выходе от величины объёмной скорости подачи исходной газовой смеси GHSV при температуре $750{ }^{\circ} \mathrm{C}$. Видно, что с увеличением GHSV концентрация непрореагировавшего метана и диоксида углерода сначала растёт, а потом выходит на плато. Напротив, концентрации водорода и моноксида углерода сначала падают, потом также выходят на плато.

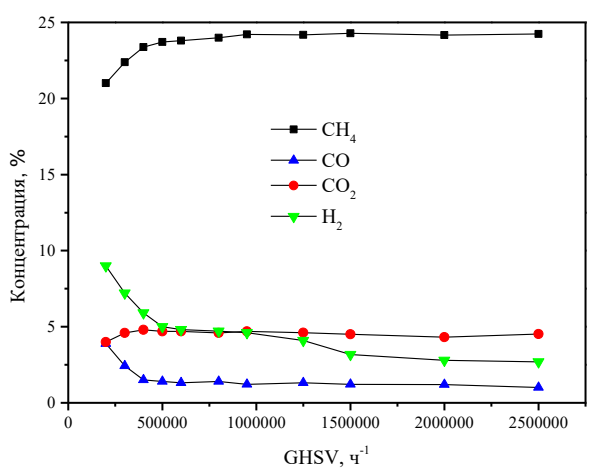

Рисунок 3 - Зона 1. Зависимость концентрации метана, моноксида углерода, диоксида углерода и водорода на выходе от объёмной скорости при $750{ }^{\circ} \mathrm{C}$

Наличие достаточных концентраций водорода и СО при малой величине входного потока свидетельствует о том, что идут как реакция полного окисления метана (2), так и паровой (3) и углекислотной конверсии (4) метана. По мере увеличения входного потока глубина протекания реакции (3) и (4) в зоне 1 существенно падает. Исходя из этого, можно предположить, что в зоне 1 в основном осуществляется быстрая реакция полного окисления метана (2).

В качестве источника кислорода во входной смеси использовали воздух, брутто- уравнение (1) реакции полного окисления метана будет иметь следующий вид:

$$
\begin{gathered}
\mathrm{CH}_{4}+0,5\left(\mathrm{O}_{2}+3,76 \mathrm{~N}_{2}\right) \rightarrow 0,75 \mathrm{CH}_{4}+0,25 \mathrm{CO}_{2}+ \\
0,5 \mathrm{H}_{2} \mathrm{O}+1,88 \mathrm{~N}_{2} .
\end{gathered}
$$

Расчёт состава смеси на выходе из зоны 1 на основе уравнения (9) показывает следующие значения: $\mathrm{CH}_{4}=26 \%$; $\mathrm{CO}=0 \%$; $\mathrm{CO}_{2}=8,7 \% ; \mathrm{H}_{2}=0 \%$. Из рисунка 3 видно, что при объёмных скоростях выше 1500000 ч-1 выходная смесь имеет состав $\mathrm{CH}_{4}=24 \%$; $\mathrm{CO}=1 \% ; \mathrm{CO}_{2}=4,5 \% ; \mathrm{H}_{2}=3 \% ; \mathrm{N}_{2}=55,6 \%$, что достаточно близко соответствует значениям, рассчитанным из уравнения (9). Следовательно, в зоне 1 при температуре $750{ }^{\circ} \mathrm{C}$ и входных потоках, превышающих 1500000 ч$^{-1}$, преимущественно протекает экзотермическая реакция полного окисления метана (2).

\section{Испытания зоны 2 и зоны 1+2}

Тестирование МКР в режиме, при котором задействована зона 2, и в комбинированном режиме с использованием зоны 1 и зоны 2 проводили также при $750{ }^{\circ} \mathrm{C}$. В первом случае (рисунок 2 б) входной поток направляли на вход зоны 2, а выходной поток регистрировали на выходе из зоны 2. Для значений входного потока 400-5000 мл/мин значения объёмной скорости GHSV лежали в диа-

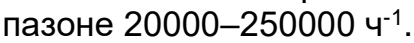

Во втором случае перекрывали вход в зону 2 МКР, а исходную реакционную смесь подавали на вход зоны 1 (рисунок 2 б). Для значений входного потока 400-5000 мл/мин значения объёмной скорости GHSV лежали в диапазоне 18000-225000 ч ${ }^{-1}$.

На рисунке 4 приведены экспериментальные зависимости концентрации реагентов на выходе для зоны 2 и для зоны 1+2 от объёмной скорости.

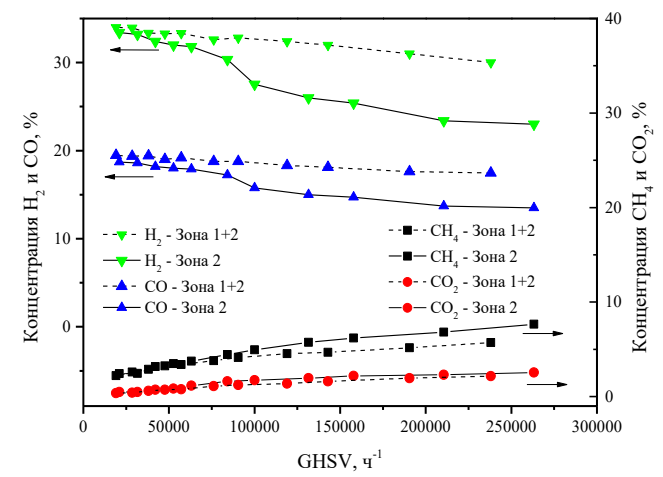

Рисунок 4 - Зависимость концентрации водорода и моноксида углерода на выходе от объёмной скорости при $750{ }^{\circ} \mathrm{C}$ для зоны 2 и зоны 1+2 
Из рисунка 4 видно, что при увеличении скорости потока концентрация водорода и моноксида углерода закономерно снижается, а метана и диоксида углерода - повышается. При малых значениях объёмной скорости конверсия метана и селективность по моноксиду углерода практически не зависит от режима, в котором испытывали МКР. Но, начиная с объёмной скорости входного потока 500000 ч$^{-1}$, различия в концентрации водорода в случае зоны 1+2 и зоны 2 становятся заметны, и при максимальной входной скорости разница составляет 7 об. \%. Такая же картина наблюдается для моноксида углерода - там разница достигает 3,8 \%. Этот фракт нельзя объяснить увеличением времени контакта на $10 \%$ для зоны 1+2 из-за того, что реакционный объём зоны 1+2 на $10 \%$ выше, чем для зоны 1. Это наглядно подтверждается (рисунок 4): даже двукратное уменьшение входного потока меняет концентрацию водорода на выходе не более чем на 3-5 \%.

Очевидно, что решающую роль в увеличении глубины протекания реакции ПОМ в случае комбинированного режима играет геометрическое сопряжение по теплу в исследуемом комбинированном режиме. Так, протекающая по всей длине канала зоны 1 высокоэкзотермическая реакция полного окисления метана (2) высвобождает тепло, которое передаётся в зону 2, где в основном идут эндотермические реакции (3) и (4). Таким образом, в исследуемом микроканальном реакторе происходит разделение процесса ПОМ на две части, в которой экзотермическая часть процесса способствует протеканию эндотермической части процесса за счёт теплового сопряжения.

\section{ЗАКЛЮЧЕНИЕ}

Проведено исследование процесса ПОМ в каталитическом МКР, составленном из двух последовательных зон - зоны экзотермической реакции полного окисления метана (зона 1) и зоны эндотермических реакций паровой и углекислотной конверсии метана (зона 2), сопряжённых по теплопередаче. Такая комбинация зон в микроканальном реакторе позволяет разгрузить энергонапряженность и, следовательно, уменьшить повышение температуры на фрронтальной кромке микроканальных пластин, обычно возникающую в ходе процесса ПОМ, а также способствует передаче тепла из зоны экзотермической реакции в зону эндотермических реакций, способствуя более полному протеканию процесса ПОМ.
Работа выполнена в рамках государственного задания Института катализа СО РАН (проект АAАA-A17-117041710082-8).

\section{СПИСОК ЛИТЕРАТУРЫ}

1. Tsang S.C. Recent advances in the conversion of methane to synthesis gas [Text] / S.C. Tsang, J.B. Claridge and M.L.H. Green // Catalysis Today. - 1995. - Vol. 23. - P. 3-15.

2. Reyniers M.-F. Catalytic Partial Oxidation. Part I. Catalytic Processes to Convert Methane: Partial or Total Oxidation [Text] / M.-F. Reyniers, C. R. H. Smet, P. G. Menon, G. B. Marin // CATTECH. - 2002. - Vol. 6. - P. 140-149.

3. Izquierdo U. Hydrogen production from methane and natural gas steam reforming in conventional and microreactor reaction systems [Text] / U. Izquierdo, V.L. Barrio, J.F. Cambra, J. Requies, M.B. Guemez, P.L. Arias, G. Kolb, R. Zapf, A.M. Gutierrez, J.R. Arraibi // Int. Journal of Hydrogen Energy. - 2012. -Vol. 37. - P. 7026-7033.

4. Liu Zhihong. Total methanation of syngas to syn-thetic natural gas over Ni catalyst in a microchannel reactor [Text] / Zhihong Liu, Bozhao Chu, Xuli Zhai, Yong Jin, Yi Cheng // Fuel. - 2012. - Vol. 95. - P. 599-605.

5. Delsman E. R. Microstructured Reactors for a Port-able Hydrogen Production Unit by Erik R. Delsman [Text] / Eindhoven: Technische Universiteit Eindho-ven, 2005. Proefschrift. - ISBN 90-3863036-0 NUR 913, $145 \mathrm{p}$.

6. Hoshmuth J. K. Catalytic partial oxidation of me-thane over monolith supported catalyst [Text] / Appl. Catal., B: Environmental. - 1992. Vol.1. - P. 89-100.

7. Schubert K. Microstructure devices for applications in thermal and chemical process engineering [Text] / K. Schubert, J. Brandner, M. Fichtner, G. Linder, U. Schygulla, A.Wenka // Microscale Thermophys. Eng. - 2001. - Vol. 5. P. 17-39.

8. Ehrfeld W., Hessel V., Loewe H. Microreactors-new technology for modern chemistry [Text] / Wein-heim: Willey-VCH; 2000.

9. Jensen K.F. Microreaction engineering: is small better? [Text] / Chem. Eng. Sci. - 2001. Vol. 56. - P. 293-303.

10. Makarshin L.L. Catalytic partial oxidation of me-thane in microchannel reactors with cocurrent and countercurrent reagent flows: An experimental com-parison [Text] / L.L. Makarshin, D.V. Andreev, A.G. Gribovskyi, V.N. Parmon // Chemical Engineering Journal. - 2011. Vol. 178. - P. 276-281.

11. Vorontsov V.A. Influence of a reaction mixture streamline on partial oxidation of methane in an asymmetric microchannel reactor [Text] / V.A. Voront-sov, A.G. Gribovskiy, L.L. Makarshin, D.V. Andreev, V.Y. Ylianitsky, V.N. Parmon // International Journal of Hydrogen Energy. - 2014. Vol. 39. P. 325-330.

ПОЛЗУНОВСКИЙ ВЕСТНИК № 42018 


\section{КОМБИНИРОВАННЫЙ МИКРОКАНАЛЬНЫЙ РЕАКТОР ДЛЯ ПАРЦИАЛЬНОГО ОКИСЛЕНИЯ МЕТАНА}

Макаршин Лев Львович, доктор химических наук, ведущий научный сотрудник лаборатории каталитических методов преобразования солнечной энергии, Федеральное государственное бюджетное учреждение науки Институт катализа им. Г.К. Борескова Сибирского отделения Российской академии наук (ИК СО РАН), makarshin@catalysis.ru.

Андреев Дмитрий Валерьевич, кандидат химических наук, старший научный сотрудник лаборатории каталитических процессов синтеза элементоорганических соединений, Федеральное государственное бюджетное учреждение науки Институт катализа им. Г.К. Борескова Сибирского отделения Российской академии наук (ИК СО PAH), andreev@catalysis.ru.

Грибовский Александр Георгиевич, кандидат технических наук, научный сотрудник лаборатории каталитических процессов синтеза элементоорганических соединений, Федеральное государственное бюджетное учреждение науки Институт катализа им. Г.К. Борескова Сибирского отделения Российской академии наук (ИК СО PAH),gribovsk@catalysis.ru. 